www.jmscr.igmpublication.org

Impact Factor (SJIF): 6.379

Index Copernicus Value: 71.58

ISSN (e)-2347-176x ISSN (p) 2455-0450

crossref DOI: _https://dx.doi.org/10.18535/jmscr/v6i4.205

Journal Of Medical Science And Clinical Research

IGM Publication

An Official Publication of IGM Publication

\title{
A Comparative study of epidural Fentanyl with Bupivacaine \& epidural Tramadol with Bupivacaine for post operative pain relief after lower abdominal Surgery
}

\author{
Authors \\ Dr Sudhir Patil, Dr Abhijeet Birnale, Dr Suresh Patil, Dr Pradeep Patil \\ ${ }^{1}$ Senior Consultant Anesthetist, ${ }^{2,3,4}$ Senior Resident (Anesthesiology) \\ PIOS Multispeciality Hospital, Jaysingpur- Sangli- Maharashtra, India \\ Corresponding Author \\ Dr Sudhir Patil
}

Senior Consultant Anesthetist, PIOS Multispecialty Hospital, Jaysingpur- Sangli- Maharashtra India

\begin{abstract}
Background: Postoperative pain control is crucial part of management of patients undergoing major abdominal surgeries. In most of the major hospital there is a gradual shift from on-demand opioid injections to epidural analgesia which is found to have excellent quality of analgesia and minimum side effects. Fentanyl, a $\mu$ opioid agonist, when used alone has short onset of action about 5 minutes and lasting for about 3-4 hours. Tramadol hydrochloride is a weak opioid having analgesic properties. Both of these drugs fentanyl and Tramadol are used widely for epidural analgesia in patients undergoing various types of surgeries. Addition of Bupivacaine prolongs analgesic effect of Fentanyl as well as Tramadol.

Aims And Objectives: To compare the efficacy of epidural Fentanyl with Bupivacaine and epidural Tramadol with Bupivacaine for postoperative analgesia in patients undergoing lower abdominal surgeries.

Materials and Methods: Sixty patients were included in our comparative study and they were randomly divided into two groups, Group A and B. Group A received $50 \mathrm{mcg}$ Fentanyl $+8 \mathrm{ml} 0.125 \%$ Bupivacaine as a bolus dose and patients in group B received $50 \mathrm{mg}$ Tramadol $+8 \mathrm{ml} 0.125 \%$ Bupivacaine as a bolus dose. The parameters like demographic characteristics, postoperative pain and postoperative analgesia were compared in both the groups.

Results: Mean duration of analgesia after epidural bolus drug was significantly higher in Group A when compared with group B. Postoperative VAS score was found to be lower in Group A as compared to group B. Hemodynamic parameter remained stable in both the groups.

Conclusion: Epidural fentanyl along with Bupivacaine has better and prolonged postoperative analgesic effect and fewer complications as compared to Tramadol with Bupivacaine in patients undergoing lower abdominal surgeries.

Keywords: Postoperative analgesia, Tramadol, Fentanyl, Complications.
\end{abstract}

\section{Introduction}

An important aspect of management of patients undergoing abdominal surgeries is providing appropriate postoperative analgesia ${ }^{[1]}$. Proper postoperative analgesia not only provides subjective comfort but also fasten recovery of the 
patient. Pain after lower abdominal surgeries is a common occurrence and unless effective analgesia is provided many patients will have moderate to severe pain ${ }^{[2]}$. It is important to understand that severe pain may not only be responsible for secondary complications like hemodynamic instability, atelectasis (due to restricted respiratory movements) but also it may be responsible for delayed recovery, prolonged hospital stay, late ambulation and increased morbidity ${ }^{[3]}$. Adequate analgesia is associated with significant reduction in perioperative cardiac morbidity, pneumonitis, pulmonary embolism, ileus, acute renal failure, and hemorrhagic shock ${ }^{[4]}$. Providing pain relief with on-demand opioid injections has largely been replaced by epidural analgesia using various agents like Tramadol and fentanyl ${ }^{[5]}$. The other drugs which can be used for epidural analgesia may include butorphanol, ropivacaine and levobupivacaine. However epidural analgesia may be associated with complications like transient parenthesis, headache, systemic toxicity and potentially devastating epidural hematoma ${ }^{[6]}$. It is important from the point of view of an anesthetist to weigh the risks of giving epidural analgesia and the potential morbidity associated with holding it. The choice of individual drug used for epidural analgesia depends upon the factors like severity of pain, presence of co morbid conditions and general condition of the patient ${ }^{[7]}$.

Tramadol is a synthetic 4-phenyl-piperidine analog of codeine and is a racemic mixture of two enantiomers. The positive enantiomer has moderate affinity for the opioid $\mu$ receptor and inhibits serotonin uptake while negative enantiomer is a potent norepinephrine synaptic release inhibitor. It has a peculiar quality of potent analgesic effect without any significant respiratory depression. Its analgesic potency has been reported to be approximately equal to pethidine by many studies. It acts by dual mechanism ${ }^{[8]}$. The main active metabolite of Tramadol is Odesmethyltramadol (M1) which is an opioid and Tramadol itself is thought to augment serotonergic and noradrenergic neurotransmission ${ }^{[9]}$.
Fentanyl is an opioid substance which acts by targeting specific $\mathrm{Mu}$-receptor and has an agonist effect. It also has agonist effect on other opioid system receptors such as the delta, and potentially the kappa-receptors. Activation of $\mathrm{Mu}$ receptor is the primary mechanism by which Fentanyl produces analgesic effect. It also causes secretion of the dopamine in the reward areas of brain consequently causing exhilaration and relaxation effects. The combined effect of activation of $\mathrm{Mu}$ receptors and increased dopamine secretion in reward areas of brain is responsible for analgesic as well as addictive effect of this drug ${ }^{[10]}$.

Major surgeries including abdominal surgeries induce profound physiological changes in the perioperative period. Postoperative pain may cause increase in sympathoadrenal and other neuroendocrine activity and cytokine production. All these sympathoadrenal and neuroendocrine activity may cause profound hemodynamic imbalance. Providing adequate postoperative analgesia can attenuate these effects and is an important part of management of these patients. Adequate analgesia may improve the quality of postoperative analgesia in comparison with systemic opioid, and hasten recovery of gut function $^{[11]}$.

We conducted this study to compare the efficacy of epidural Fentanyl with Bupivacaine and epidural Tramadol with Bupivacaine for postoperative analgesia in patient undergoing lower abdominal surgeries.

\section{Materials and Methods}

This was a prospective comparative study conducted in a teaching institute. The duration of the study was 1 year. After taking written informed consent 60 patients above 18 years of age undergoing lower abdominal surgeries were included in this study. Taking into consideration previous studies with an alpha error of 0.05 and a power of $80 \%$ the minimum sample size 30 patients per group was found to be appropriate so we included 30 patients in each group. Detailed history was taken in all patients with an emphasis 
on indication and type of abdominal surgery, type of anesthesia during surgery, perioperative and immediate postoperative complications.

Premedication was done with alprazolam and tablet ranitidine administered orally with a sip of water on the evening before surgery in cases of elective surgeries. After intravenous (i.v.) cannulation and attachment of monitor, anesthesia was induced with fentanyl i.v. plus propofol i.v. Tracheal intubation was facilitated with vecuronium bromide $0.1 \mathrm{mg} / \mathrm{kg}$. Maintenance of i.v. anesthesia was done with isoflurane, nitrous oxide in oxygen and fentanyl. Following induction of anesthesia, patients were placed in the lateral decubitus position and an 18-gauge Tuohy needle was introduced at the $\mathrm{T} 10-11$ interspace in the midline. Epidural catheter was placed after locating the epidural space with the loss of resistance technique. It was ensured that no cerebrospinal fluid or blood backflows from the epidural catheter. Patients were randomized into two groups:

Group A: Patients in this group received $50 \mathrm{mcg}$ Fentanyl $+8 \mathrm{ml} 0.125 \%$ Bupivacaine as a bolus dose.

Group B: Patients in this group received $50 \mathrm{mg}$ Tramadol+ $8 \mathrm{ml} 0.125 \%$ Bupivacaine as a bolus dose.

The drugs were given epidurally as a bolus dose at the time of incisional wound closure. Postoperative data for pain, sedation score, hemodynamic parameters and spo 2 were recorded at $0,15,30,60$ minutes and then hourly up to 12 hours.

Data was analyzed by using SPSS 16.0 version. The data was presented as mean and standard deviation. Chi-square test and student ' $t$ ' tests were used for difference in the demographic data. Hemodynamic variables were analyzed using paired' test. For statistical comparisons $\mathrm{P}$ value less than 0.05 was taken as significant.

\section{Inclusion Criteria}

- Patients undergoing lower abdominal surgeries.
- $\mathrm{ASA}$ I/II

- Age more than 18 years

- Patients who gave informed consent to be part of the study.

\section{Exclusion Criteria}

- Patients who refused to give the consent.

- ASA III or more.

- Patients in whom epidural analgesia is contraindicated (Local infection, coagulopathy, allergic to drugs etc).

\section{Results}

This study was a prospective comparative study in which 60 patients with ASA I and II undergoing lower abdominal surgeries for various pathologies were included as per inclusion criteria. Patients were excluded if they had any factor of exclusion criteria. Patients were divided into 2 groups Group A: (Patients in this group received $50 \mathrm{mcg}$ Fentanyl $+8 \mathrm{ml} 0.125 \%$ Bupivacaine as a bolus dose) and Group B (Patients in this group received $50 \mathrm{mg}$ Tramadol $+8 \mathrm{ml} 0.125 \%$ Bupivacaine as a bolus dose.).

\section{Demographic Data}

Out of Total 60 cases there were 38 males and 22 females with a $\mathrm{M}$ : $\mathrm{F}$ ratio of 1:0.57. In group A there were 20 males and 10 females while in group B there were 18 males and 12 females

\section{Gender Distribution}

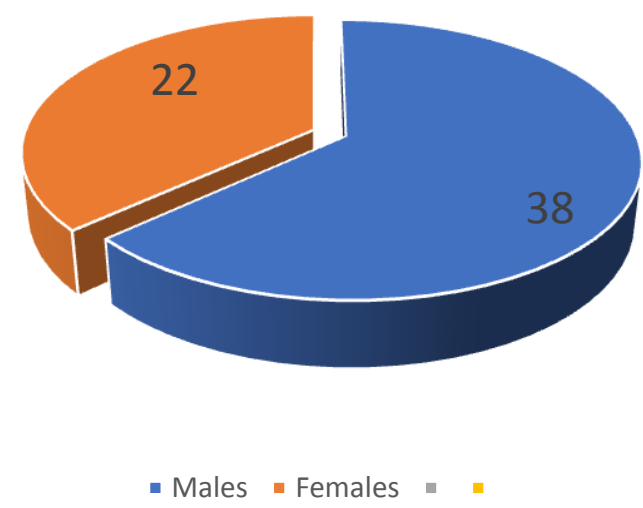

Figure 1: Gender Distribution of the studied cases 
Out of the studied cases Group A had a mean age of 43.42years and group B had a mean age of 40.28 years.

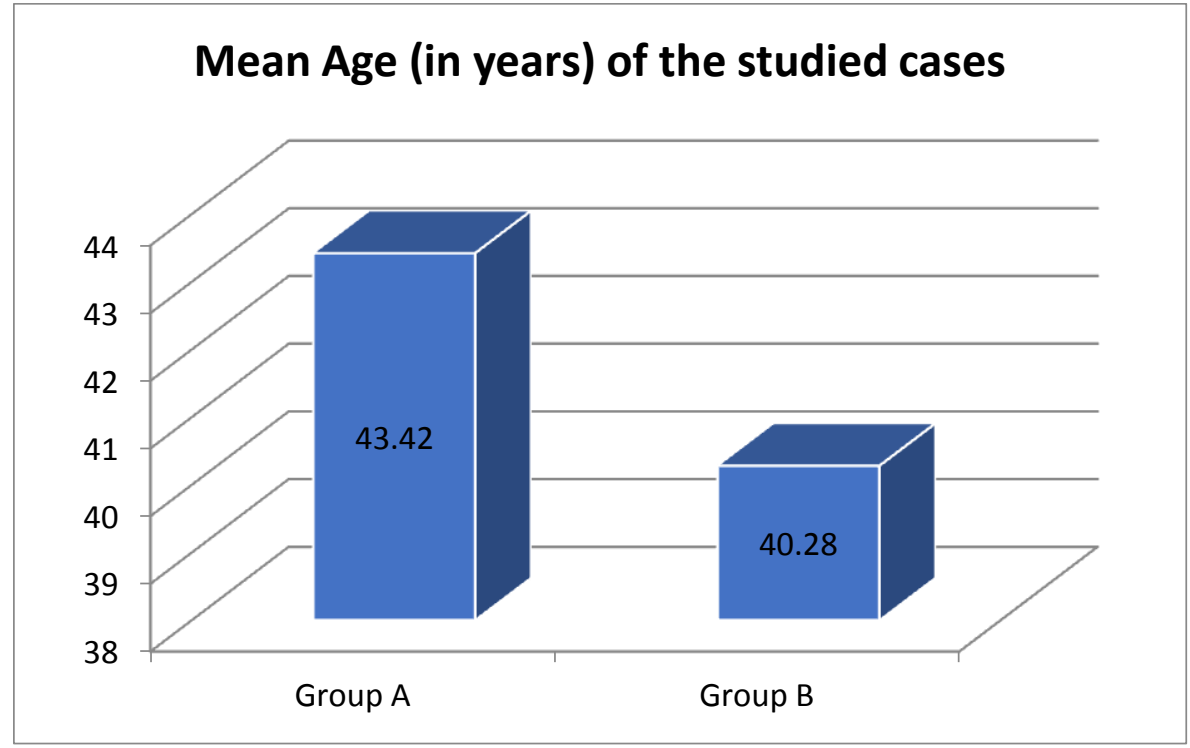

Figure 2: Mean Age Of the studied cases

In group A $12(40 \%)$ patients belonged to ASA I percentage of patients with ASA I and ASA II was and $18(60 \%)$ patients belonged to ASA II. The $\quad 46.66 \%$ and $53.33 \%$ respectively in group B.

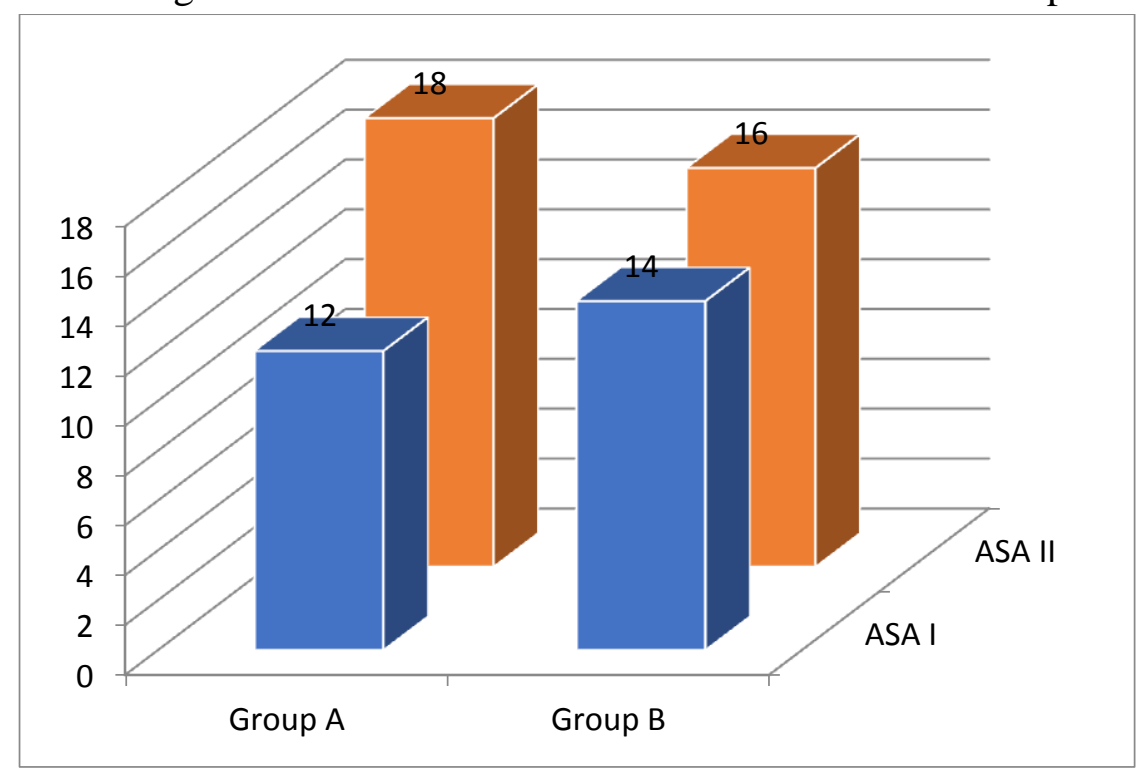

Figure 3: ASA grades of studied cases

Table 1: Demographic data in studied cases

\begin{tabular}{|l|}
\hline Parameters \\
\hline No of cases \\
\hline Mean Age \\
\hline Gender \\
Males \\
Females \\
\hline ASA \\
I \\
II \\
\hline
\end{tabular}

Comparison of mean duration of the surgeries showed that the mean duration of the surgery was

\begin{tabular}{|c|c|}
\hline Group A & Group B \\
\hline 30 & 30 \\
\hline 43.42 & 40.28 \\
\hline & \\
\hline 10 & 18 \\
\hline $12(40.00 \%)$ & 12 \\
\hline $14(46.66 \%)$ & $16(50.00 \%)$ \\
\hline
\end{tabular}

$72+/-18.72$ minutes in group A while this duration was $68+/-16.34$ minutes in Group B 


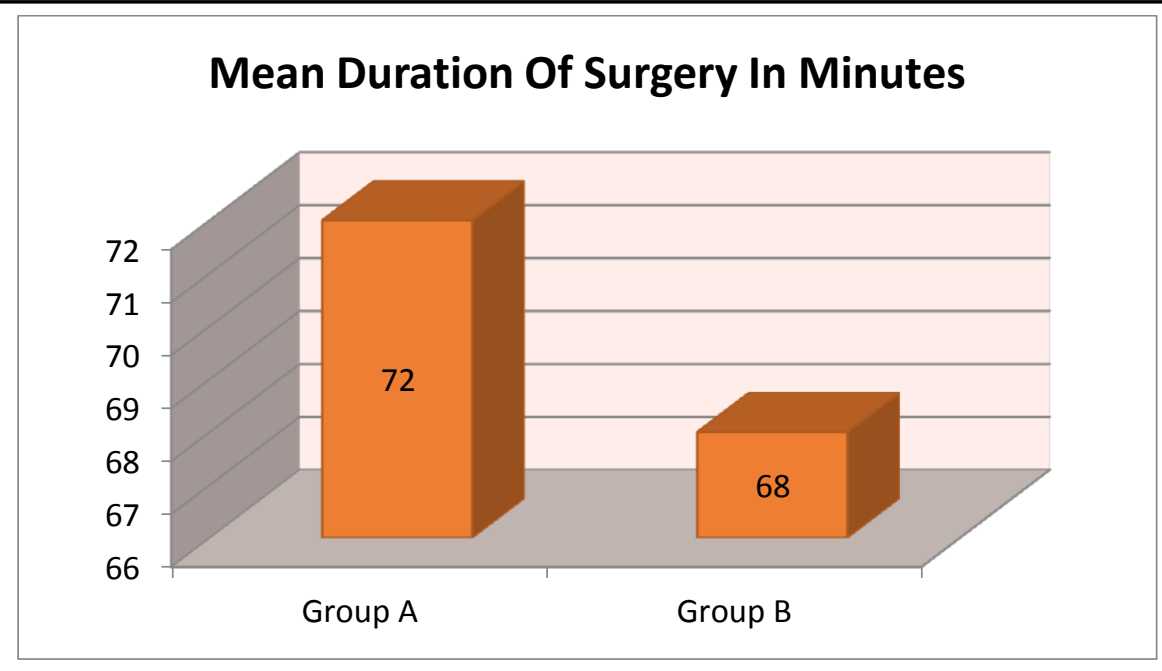

Figure 4: Mean duration of the surgery (in Minutes)

The test of significance applied showed that $\mathrm{p}$ value was 'not significant' and hence mean duration of surgery in both the groups was found to be comparable without any statically significant difference.

Table 2 : Mean Duration of surgery

\begin{tabular}{l|c}
\hline & Mean Duration Of Surgery \\
\hline Group A & $72+/-18.72 \mathrm{Min}$ \\
Group B & $68+/-16.34 \mathrm{Min}$ \\
P Value & 0.38 \\
P value & Not Significant \\
\hline
\end{tabular}

The analysis of mean VAS score in group A and Group B revealed that mean VAS score was significantly less in Group A at 30,60 minutes and rest of the time till 12 hour postoperatively.

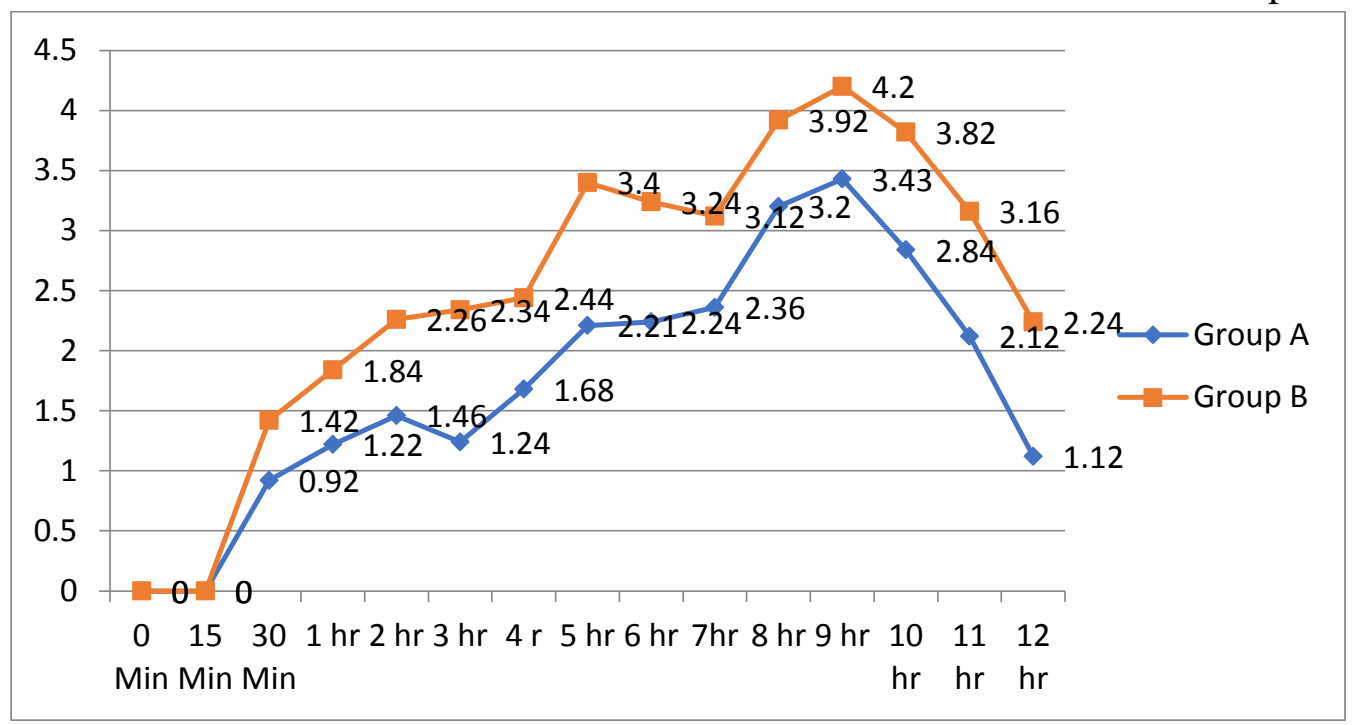

Figure 5: Mean VAS scores in studied cases.

Mean Duration of analgesia was found to be 472.24 minutes in group A while in Group B it was 378.64 minutes. 


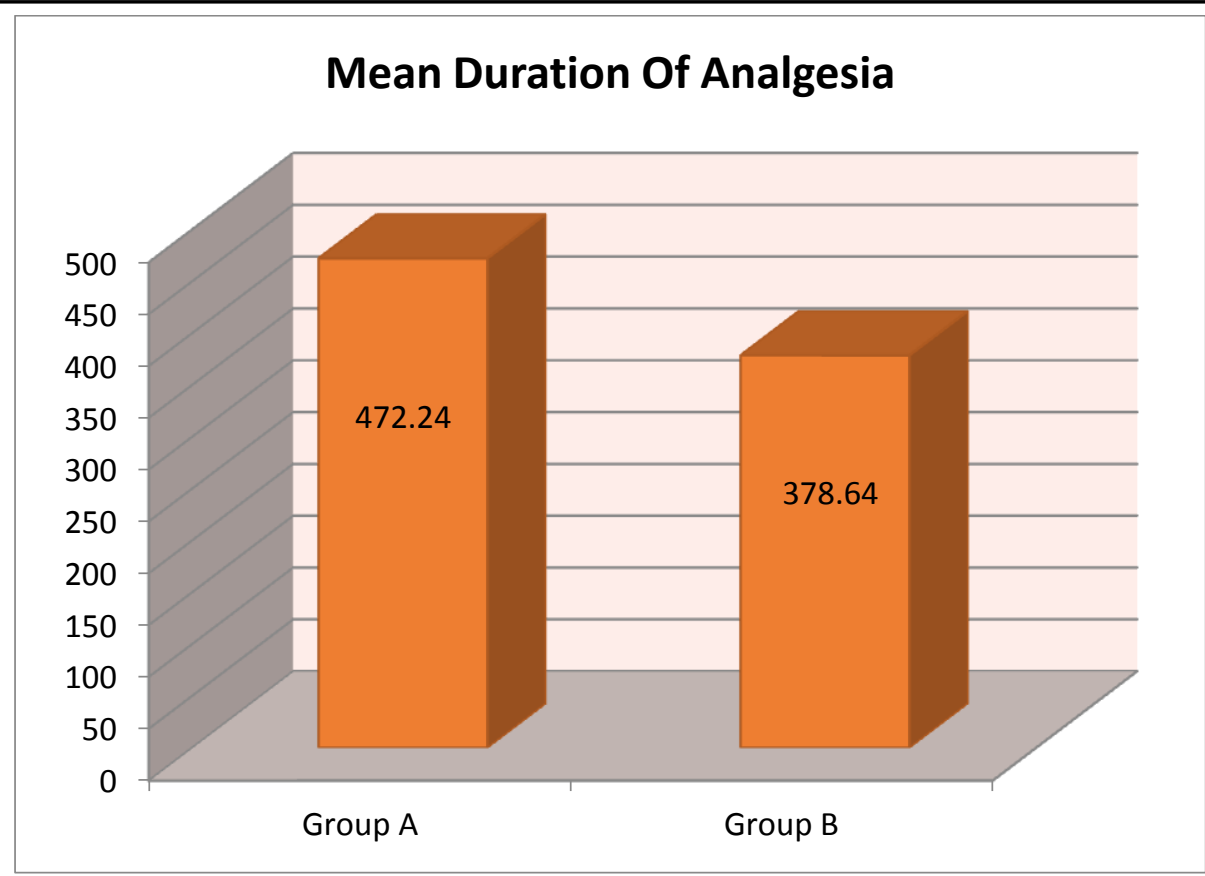

Figure 6: Mean duration of analgesia in studied cases

Finally an analysis of adverse effects of epidural analgesia was done in both the groups. Group A was found to have less incidence of nausea and vomiting than group B while respiratory depression, sedation and pruritis was found to be more common in Group A than Group B.

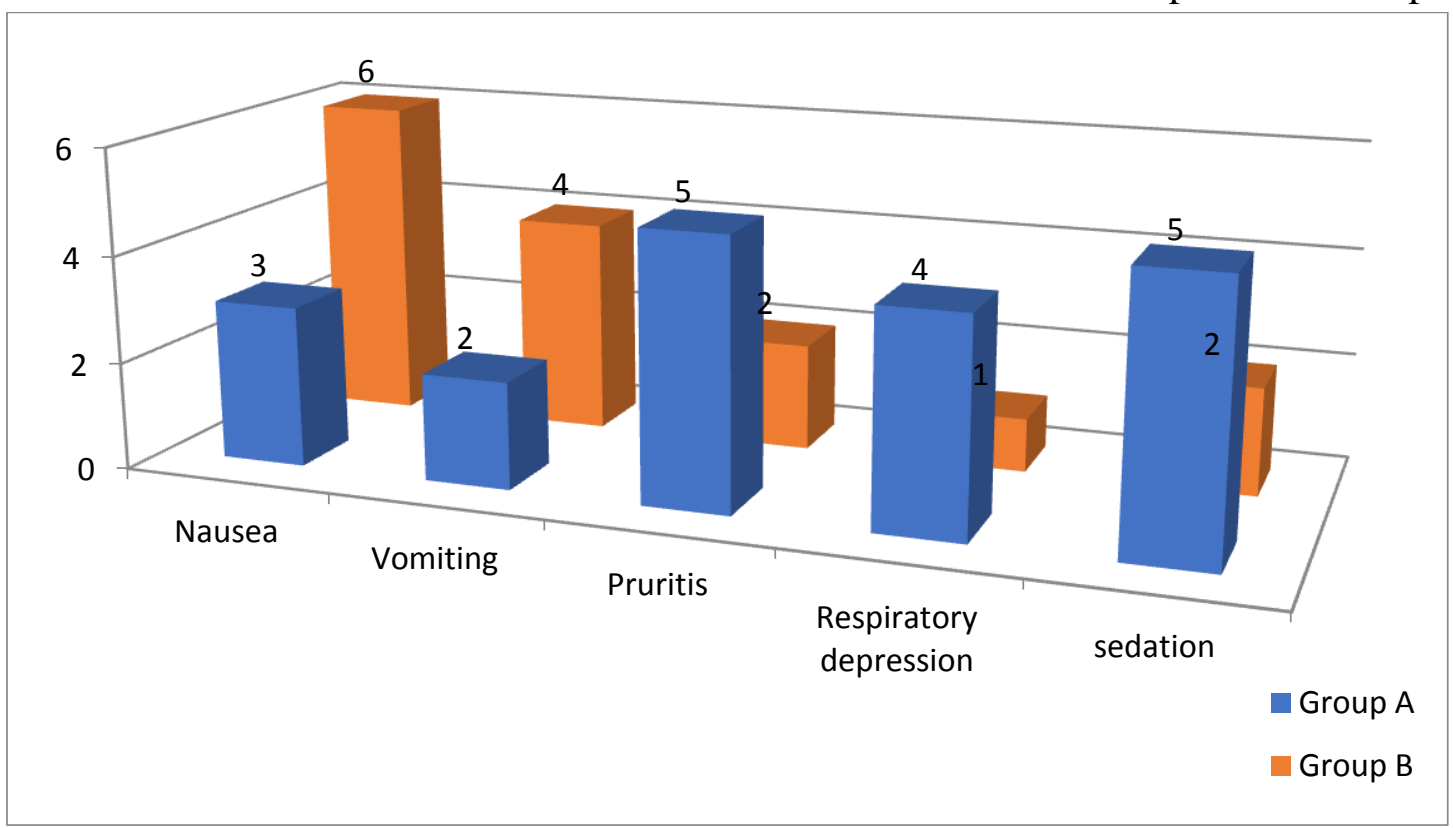

Figure 7: Complications in studied cases

\section{Discussion}

Despite improvements in anesthetic care, major surgical operations are still followed by significant pain, organ dysfunction and delayed ambulation $^{[12]}$. It has been proved in many randomized controlled trials that sufficient pain relief will improve the surgical outcome and will reduce the morbidity resulting into early discharge and consequently will reduce the financial burden on the patients ${ }^{[13,14]}$. In that sense adequate and optimum postoperative analgesia is one of the most crucial aspects of patient management ${ }^{[15]}$.

We conducted this study to compare the efficacy of epidural Fentanyl with Bupivacaine and epidural Tramadol with Bupivacaine for postoperative analgesia in patient undergoing 
lower abdominal surgeries. Our study found that epidural fentanyl with Bupivacaine has a better analgesic effect as compared to epidural Tramadol with Bupivacaine. We moreover found that the adverse effects like respiratory depression, urinary retention and pruritis were more common in the group which received fentanyl and nausea and vomiting was found to be more common in Tramadol group. One of the most important side effects, respiratory depression, was found to be more commonly seen in fentanyl group.

Epidural Tramadol for post operative analgesia has been studied extensively by many authors. Tramadol alone or as an adjuvant to other anesthetic agents have been used frequently in post operative period. Anil P. Singh et al in their study of Ninety patients undergoing abdominal surgery under general anesthesia compared ropivacaine and ropivacaine along with Tramadol $1 \mathrm{mg} / \mathrm{kg}$ and $2 \mathrm{mg} / \mathrm{kg}$. The authors found that Tramadol $2 \mathrm{mg} / \mathrm{kg}$ with ropivacaine $(0.2 \%)$ was more effective and responsible for longerduration analgesia than Tramadol $1 \mathrm{mg} / \mathrm{kg}$ with ropivacaine $(0.2 \%)^{[16]}$.

Similarly C N $\mathrm{H}$ Tan et al conducted a double-blind, randomized controlled trial to investigate the analgesic and adverse effects of three commonly used concentrations of thoracic epidural fentanyl with Bupivacaine in patients undergoing thoracotomy. The authors found that fentanyl $5 \mu \mathrm{g}$ ml-1 with Bupivacaine $0.1 \%$ provides the optimum balance between pain relief and side effects ${ }^{[17]}$.

In another study Prakash $\mathrm{S}$ et al conducted a prospective study to compare the analgesic efficacy of three doses of Tramadol, administered caudally with Bupivacaine, in providing postoperative pain relief in abdominal surgeries. Eighty patients undergoing inguinal herniotomy were randomly allocated to receive Bupivacaine $0.25 \% \quad 0.75 \mathrm{ml} \quad \mathrm{kg}-1 \quad$ (Group B; $\mathrm{n}=20$ ), Bupivacaine $0.25 \% 0.75 \mathrm{ml} \mathrm{kg}-1$ with Tramadol $1 \mathrm{mg} \mathrm{kg}-1$ (Group BT1; n=20), Bupivacaine $0.25 \% 0.75 \mathrm{ml} \mathrm{kg}-1$ with Tramadol $1.5 \mathrm{mg} \mathrm{kg}-1$ (Group BT1.5; $\mathrm{n}=20$ ), or Bupivacaine $0.25 \% 0.75$ $\mathrm{ml} \mathrm{kg-1}$ with Tramadol $2 \mathrm{mg} \mathrm{kg-1}$ (Group BT2; $\mathrm{n}=20$ ) by the caudal route immediately after induction of general anaesthesia. Heart rate, arterial pressure and oxygen saturation were monitored. Postoperative pain was assessed at regular intervals for $24 \mathrm{~h}$ using All India Institute of Medical Sciences pain score. The authors found that Caudal Tramadol $2 \mathrm{mg} \mathrm{kg}-1$, combined with Bupivacaine $0.25 \% \quad 0.75 \mathrm{ml} \mathrm{kg}-1$, provided longer duration of postoperative analgesia and reduced requirement for rescue analgesic compared with Tramadol $1 \mathrm{mg} \mathrm{kg}-1$ or $1.5 \mathrm{mg}$ $\mathrm{kg}-1$ in children undergoing inguinal herniotomy ${ }^{[18]}$. Similar results were found in the studies conducted by Swathi $\mathrm{N}$ et al and Delilkan $\mathrm{AE}$ at al ${ }^{[19,20]}$.

\section{Conclusion}

Epidural Fentanyl and Bupivacaine is associated with better postoperative analgesic effect than epidural Tramadol and Bupivacaine in postoperative period in patients undergoing lower abdominal surgeries.

\section{Conflict of Interest: None}

\section{References}

1. Garimella V, Cellini C. Postoperative Pain Control. Clinics in Colon and Rectal Surgery. 2013;26(3):191-196.

2. Shoar S, Esmaeili S, Safari S. Pain Management After Surgery: A Brief Review. Anesthesiology and Pain Medicine. 2012;1(3):184-186.

3. Seeling W, Rockemann M. [Influence of postoperative pain on morbidity and mortality.]. Schmerz. 1993 Jun;7 (2):85-96.

4. Luo J, Min S. Postoperative pain management in the postanesthesia care unit: an update. Journal of Pain Research. 2017;10:2687-2698.

5. Mezei M, Mihalik Z, Pénzes I. [Continuous postoperative epidural analgesia in abdominal surgery using 
$\begin{array}{llll}\text { ropivacain]. Magy } & \text { Seb. } & 2002\end{array}$ Apr;55(2):87-91.

6. Kang XH, Bao FP, Xiong XX, Li M, Jin TT, Shao J, Zhu SM. Major complications of epidural anesthesia: a prospective study of 5083 cases at a single hospital. Acta Anaesthesiol Scand. 2014 Aug;58(7):858-66.

7. De Leon-Casasola OA, Lema MJ. Postoperative epidural opioid analgesia: what are the choices? Anesth Analg. 1996 Oct;83(4):867-75.

8. Young JWS, Juurlink DN. Tramadol. CMAJ : Canadian Medical Association Journal. 2013;185(8):E352.

9. Grond S, Sablotzki A. Clinical pharmacology of tramadol. Clin Pharmacokinet. 2004;43(13):879-923.

10. Stanley TH. Fentanyl. J Pain Symptom Manage. 2005 May;29(5 Suppl):S67-71.

11. Bauer M, George JE, Seif J, Farag E. Recent Advances in Epidural Analgesia. Anesthesiology Research and Practice. 2012;2012:309219.

12. Korean Knee Society. Guidelines for the Management of Postoperative Pain after Total Knee Arthroplasty. Knee Surgery \& Related Research. 2012;24(4):201-207.

13. Chelly JE, Gebhard R, Greger J, Al Samsam T. Regional anesthesia for outpatient orthopedic surgery. Minerva Anestesiol. 2001;67:227-232

14. Koh IJ, Kang YG, Chang CB, Do SH, Seong SC, Kim TK. Does periarticular injection have additional pain relieving effects during contemporary multimodal pain control protocols for TKA?: A randomised, controlled study. Knee 2012;19:253-259.

15. Macintyre PE. Intravenous patientcontrolled analgesia: one size does not fit all. Anesthesiol Clin North America. 2005;23:109-123.
16. Singh AP, Singh D, Singh Y, Jain G. Postoperative analgesic efficacy of epidural tramadol as adjutant to ropivacaine in adult upper abdominal surgeries. Anesthesia, Essays and Researches. 2015;9(3):369-373.

17. Tan CN, Guha A, Scawn ND, Pennefather SH, Russell GN. Optimal concentration of epidural fentanyl in bupivacaine $0.1 \%$ after thoracotomy. $\mathrm{Br} \mathrm{J}$ Anaesth. 2004 May;92(5):670-4. Epub 2004 Mar 19.

18. Prakash S, Tyagi R, Gogia AR, Singh R, Prakash S. Efficacy of three doses of tramadol with bupivacaine for caudal analgesia in paediatric inguinal herniotomy. Br J Anaesth. 2006 Sep;97(3):385-8. Epub 2006 Jun 23.

19. Swathi N, Ashwini N, Shukla MI. Comparative study of epidural bupivacaine with butorphanol and bupivacaine with tramadol for postoperative pain relief in abdominal surgeries. Anesthesia, Essays and Researches. 2016;10(3):462-467.

20. Delilkan AE, Vijayan R. Epidural tramadol for postoperative pain relief. Anaesthesia. 1993 Apr;48(4):328-31. 